\title{
A Study of Independent Director's Reputation Incentive Mechanism Based on the Principal-Agent Theory
}

\author{
Xiaoning $\mathbf{L V}^{1}$, Yang $\mathrm{LIU}^{2}$ \\ ${ }^{1}$ Dalian Jiaotong University, Dalian, China \\ ${ }^{2}$ Dalian University of Technology, Dalian, China
}

\begin{abstract}
This paper applies principal-agent theory to research into the incentive compatibility problems of the independent directors (IDs). The traditional fixed-pay system could preserve the independence of IDs, however, lacking of incentives, the performance-related incentive mechanisms have great impact on IDs' independence which is the core of the system. This paper considers reputation incentive mechanism (RIM) as an effective way to solve this dilemma. The results, after our study, show that appropriate RIM can maintain IDs' independence as well as their incentive compatibility. Furthermore, taking the market-signal theory as reference, this paper sets up a model to introduce another function of RIM, which can help the company to identify the different roles of IDs.
\end{abstract}

Keywords: reputation incentive mechanism, independent directors, principal-agent relationship, market signal

\section{1 引言}

2001 年我國正式開始引入獨立董事制度, 希望通 過引入獨立的外部董事, 以分散企業的控制權, 從而 彌補傳統法人治理結構的缺陷。但從實踐來看, 該制 度並沒有達到其預期的功能定位。本文從委託代理的 角度出發, 研究獨立董事制度不盡人意的原因, 並提 出相應的解決途徑。

邱風，張青通過建立博弯模型分析了我國獨立董 事失效的原因,分析結果認為,最根本的原因是獨立董 事缺乏有效的激勵約束機制[1]。根據委託一代理理論, 獨立董事具有資訊優勢, 是代理人, 具有資訊劣勢的是 獨立董事的最終委託人 [2]。獨立董事本質上代理人的 身份決定了他與企業經營者一樣可能存在逆向選擇和 道德風險行為, 隨之產生二級代理成本, 或稱 “監督 監督者” 的成本。實際上崖生這種成本的根本原因是 存在資訊不對稱。獨立董事的職能是監督董事會和經 理層的行為, 並對公司的營運狀況提出有益的建議。 但是這些工作很難被具體量化, 是一種隱性行為。激 勵機制的設計就是委託人希望通過一種分配制度的安 排來獎勵獨立董事, 以促使其提供更有利於委託人的 行為, 以儘量減少代理成本。

獨立董事發揮作用的基礎在於其獨立性。只有保 持與公司獨立, 獨立董事才能有效抑制和約束大股東 和經理層的機會主義行為。保持獨立性要求獨立董事 不能與公司之間存在任何重大經濟利益關係, 但是作
為 “理性人” 的獨立董事, 必須要在一定的激勵條件 下，才願意履行其職能。羅黨論認為獨立董事報酬是 作為激勵獨立董事努力工作、發揮其在公司治理結構 中重要作用的主要手段,其合理與否直接影響到獨立 董事積極性的發揮[3]。張安中指出：獨立董事本質上 也是代理人, 是企業的經營者而不是所有者, 屬於職 業企業家隊伍中的一個組成部分, 要獨立董事真正落 實制度的初衷, 沒有足夠的激勵只能是一廂情願。因 此, 必須給予獨立董事足夠的激勵, 才能使獨立董事 充分發揮作用。所以薪酬機制一定要合理, 既不能太 低, 要能激發獨立董事努力盡責行使職權, 又不能太 高而使其對公司產生依賴感,這就產生了一個獨立董 事的 “獨立性悖論”。鐘偉談到: 如果獨立董事從中 無利可圖, 那麼獨立董事就會獨立得連董事會都經常 缺席, 如果獨立董事從中或明或暗分一杯美, 則獨立 董事相對于賜予美美者則已然不獨立了。簡新華,石華 巍從利益相關者理論角度,分析了獨立董事獨立性的 內涵,認為 “獨立性悖論” 不是不可克服的,獨立董事 也是企業的利益相關者之一,作為企業法人利益的維 護者和其他利益相關者利益的協調人,分享企業剩餘 並不一定會喪失 “獨立性” [4]。這個研究結論為本文 從代理人角度來研究獨立董事的激勵問題提供了支 持。

Holmstrom 建立了代理人一聲譽模型,直接證明了 聲譽可以作為顯性激勵契約的替代物,從而為聲譽對 企業經營者激勵效應問題的研究開了先河 [5]。在獨立 
董事的市場聲譽方面, Fama and Jensen 首先提出由董 事執業市場激發的聲譽機制能夠促進獨立董事的監督 能力,獨立董事聲譽越高,越能保持其獨立性,從而具有 較高的降低代理成本的能力[6]。因此, 要使獨立董事 也真正關心公司的經營決策, 聲譽激勵制度能發揮較 好的作用。

傳統的獨立董事薪酬支付方式主要是固定津貼制, 包括年費和出席會議費,同時還可能有委員會成員費 和委員會會議費等,一般與公司業績無關, 這樣做可以 在一定程度上保持獨立董事的獨立性, 但是與努力程 度無關的固定薪酬制度不足以激發其工作熱情。近年 來更多的企業嘗試將獨董薪酬與公司業績相關聯, 這 樣可以提高激勵力度, 但是如果把握不好激勵尺度, 其獨立性就難以保證。所以要解決這種兩難境況, 就 需要有更加合理的激勵方式。本文通過分析試圖說 明, 聲譽激勵機制可以作為傳統薪酬支付方式合理有 效的補充, 應該作為獨立董事制度改革的一個方向。

\section{2 聲譽激勵機制的理論分析}

\section{1 假設}

假設 1 ): 委託人是風險中性者, 獨立董事是風險 規避者, 此假定符合一般委託代理關係。用 $u$ 代表效 用, $w$ 代表貨幣收益, 則委託人與獨立董事的效用函 數可分別表示為:

$$
u_{1}=w_{1}, \quad u_{2}=-e^{-\rho w_{2}}
$$

意味著委託人的效用函數可用其貨幣收益表示, 而獨立董事的效用函數則是具有風險規避的特性, 具 有下凹的形狀, 這裏 $\rho$ 是絕對風險規避度。

假設 2): 把影響公司績效的因素歸為兩類: 獨立 董事的因素, 除獨立董事以外的其他因素。設 $\alpha$ 是代 表獨立董事努力程度的一維連續變數, $\theta$ 是除獨立董 事以外的其他影響公司績效的因素, 並且 $\theta$ 獨立於 $\alpha$, 是均值為 $T$, 方差為 $\sigma^{2}$ 的正態隨機變數, 故產出 函數

$$
\pi=f(\alpha)+\theta, \quad f^{\prime}(\alpha)>0,
$$

且 $E(\pi)=f(\alpha)+T ; \operatorname{Var}(\pi)=\sigma^{2}, \pi$ 是 $\alpha$ 的增函數。

假設 3): 獨立董事可以選擇自己的努力程度, 並 通過理性分析決定使自己效用最大化的最優努力程度 $\alpha$, 但是委託人無法觀察到努力程度這一隱性行為, 只能通過與努力程度相關的產出水準評價獨立董事的 行為, 並支付一定報酬, 設獨立董事的薪酬函數為

$$
S=A+\beta \pi, \quad \beta \in(0,1)
$$

其中 $A$ 是固定薪酬, $\beta$ 是激勵程度, 代表獨立董 事分享的產出份額。 $\beta=0$ 意味著獨立董事不承擔任何 風險, 只接受固定薪酬, $\beta=1$ 代表獨立董事不具有任 何獨立性, 獲得全部收益, 當然這是不可能的情況。 此假設意味著想保持完全的獨立性, 獨立董事只能接 受固定薪酬。

假設 4): 存在聲譽激勵機制的情況下, 獨立董事 的收益除公司支付的薪酬外還應有社會聲譽這一部 分, 聲譽收益應與其所代表公司業績相關, 公司業績 越好獨立董事的名聲越好。將其聲譽收益貨幣化設:

$$
R=k(\pi-\bar{\pi}), \quad k>0
$$

其中, $k$ 代表聲譽激勵係數, $\bar{\pi}$ 代表股東的預期最 低收益, 說明聲譽收益取決於激勵係數以及公司業績 超過股東期望收益的部分。另外, 獨立董事付出努力 會產生成本, 設

$$
C(\alpha)=\frac{b \alpha^{2}}{2}, \quad C^{\prime}(\alpha)=b \alpha>0,
$$

其中 $b>0$, 是成本係數。這裏邊際成本遞增, 也就 是隨努力付出的增加, 成本會逐漸增加, 並且這種關 係是加速的。

\section{2 模型及分析}

\subsection{1 確定性等值}

由於影響股東和獨立董事最終效用的變數 $\pi$ 有一 定的隨機性, 不利於比較求解, 所以我們需要求出雙 方收益的確定性等值。由以上假設可得獨立董事的最 終貨幣收益為:

$$
\begin{aligned}
w_{2} & =S+R-C \\
& =A+(\beta+k)(f(\alpha)+\theta)-k \bar{\pi}-\frac{b \alpha^{2}}{2}
\end{aligned}
$$

由 $\theta$ 的分佈得 $w_{2} \sim N\left(\omega,(\beta+k)^{2} \sigma^{2}\right)$, 其中

$$
\omega=A+(\beta+k)(f(\alpha)+T)-k \bar{\pi}-\frac{b \alpha^{2}}{2}
$$

已知獨立董事的效用函數有風險規避的特性, 由 確定性等值的定義可求獨立董事收益的確定性等值 $\overline{w_{2}}=\omega-\frac{(\beta+k)^{2} \sigma^{2} \rho}{2}$ 。

同樣, 委託人的貨幣收益可以表示為:

$$
w_{1}=\pi-S=(1-\beta) \pi-A,
$$

因為風險中性的特性, 其效用的期望值等於收益 
期望值的效用, 因此委託人收益的確定性等值 $\overline{w_{1}}=(1-\beta)(f(\alpha)+T)-A$ 。

\subsection{2 帕累托最優解}

從全公司的角度來看, 如果不存在資訊不對稱, 獨立董事選擇自己的努力程度, 股東知道其努力程 度, 並根據這一努力給予相應的報酬, 雙方以共同的 目標最大化為出發點, 可達帕累托最優解:

$$
\max .\left(\overline{w_{1}}+\overline{w_{2}}\right)=(1+k)(f(\alpha)+T)-k \bar{\pi}-\frac{b \alpha^{2}}{2}-\frac{(\beta+k)^{2} \sigma^{2} \rho}{2}
$$

解這個最優規劃問題，對 $\alpha$ 求導可得：

$$
(1+k) f^{\prime}(\alpha)=b \alpha
$$

令 $\alpha_{1}$ 滿足 (1) 式。

\subsection{3 一般情況}

由於公司支付獨立董事薪酬, 只能依據可觀測的 結果一一公司運行績效。但是公司的績效並不是獨立 董事努力程度這一單一因素能夠決定的, 所以在資訊 不對稱的情況下, 不能達到帕累托最優的結果。此時 雙方的行為選擇可視為一個兩步的動態博弯模式, 首 先是獨立董事選擇自己的行為以使其效用最大化:

$$
\max \cdot \overline{w_{2}}=A+(\beta+k)(f(\alpha)+T)-k \bar{\pi}-\frac{b \alpha^{2}}{2}-\frac{(\beta+k)^{2} \sigma^{2} \rho}{2}
$$

求解最優化問題，對 $\alpha$ 求導可得：

$$
(\beta+k) f^{\prime}(\alpha)=b \alpha
$$

令 $\alpha_{2}$ 滿足 (2) 式。

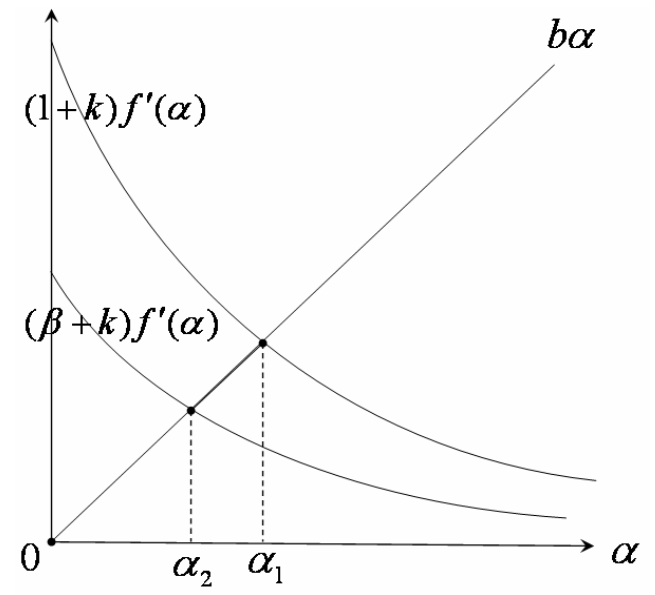

圖 1. 一般情況

Figure 1. General situation

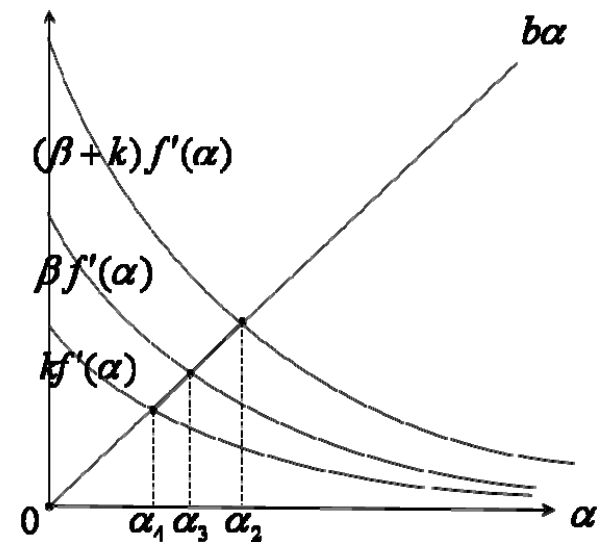

圖 2. 幾種特殊情況

Figure 2. Special circumstances

由於 $\beta \in(0,1)$, 所以如圖 1 所示: $(\beta+k) f^{\prime}(\alpha)$ 在 $(1+k) f^{\prime}(\alpha)$ 下方, 因此有 $\alpha_{2}<\alpha_{1}$, 即此時獨立董事選 擇的努力程度小於帕累托最優時的水準。

\subsection{4 幾種特殊情況}

幾種特殊情況如圖 2 所示。

1) $k=0, \beta=0$, 這就意味著沒有聲譽激勵機 制, 採用固定薪酬。上述獨立董事的最優選擇轉化為:

$$
\max \cdot \overline{w_{2}}=A-\frac{b \alpha^{2}}{2}
$$

這樣獨立董事的理性選擇就是乾脆不努力, 因為 收益一定的情況下, 努力越多成本越多, 當然 $\alpha=0$ 是 最優選擇, 但是獨立董事並不能完全不做事, 那樣委 託人不會支付薪酬, 所以例行的會議, 表決是必須參 加的, 這就使得獨立董事只存留於形勢, 沒有動力真 正做事情。雖然, 看起來好像是極端的分析, 但實際 上目前我國獨立董事如同花瓶的現狀多少說明著這種 情況。

2) $k=0, \quad \beta \neq 0$, 即沒有聲譽激勵機制, 但是薪 酬部分來自於公司收益。此時最優化獨立董事的收 益, 將 $k=0$ 代入 (2) 式得到

$$
\beta f^{\prime}(\alpha)=b \alpha \text {, 令 } \alpha_{3} \text { 滿足此等式。 }
$$

3) $\beta=0, k \neq 0$, 即有聲譽激勵機制, 但採用固定 薪酬。同理將 $\beta=0$ 代入 (2) 中得

$k f^{\prime}(\alpha)=b \alpha$, 令 $\alpha_{4}$ 滿足此等式。

把三種特殊情況下獨立董事的努力程度與一般情 況下的結果比較, 如圖 2 示, 可以得到如下關係:

$0<\alpha_{4}<\alpha_{3}<\alpha_{2}$, 這裏 $\alpha_{4}<\alpha_{3}$ 是由於聲譽激勵機 制給獨立董事帶來的報酬比較難於衡量, 且屬於間接 
收益, 故這裹假設 $k$ 較小, $k<\beta$, 但實際情況 $k$ 與 $\beta$ 的 關係不存在大小的比較關係。值得關注的是在這三種 特殊情沉下獨立董事的努力程度都小於我們假設的一 般情況, 即聲譽激勵與公司利益分紅都存在的情況。

也就是說聲譽激勵機制以及薪酬的結構都是會影 響獨立董事理性選擇自己的努力程度。存在聲譽激勵 機制或分享公司收益的薪酬制度的情況下, 獨立董事 採取的努力程度要好於沒有這兩種機制的情況。

\subsection{5 股東決策}

以上模型說明了動態博亦第一步, 下面研究博亦 的第二步股東決策。

委託人在有條件約束的情況下最大化自己的效 用，可表示為:

$$
\max \cdot \overline{w_{1}}=(1-\beta)(f(\alpha)+T)-A
$$

s.t.

$$
\begin{gathered}
\overline{w_{2}} \geq w_{0} \\
(\beta+k) f^{\prime}(\alpha)=b \alpha
\end{gathered}
$$

其中 $w_{0}$ 是獨立董事接受工作的最低收益, 可以看 作一種機會成本, 既要滿足參與約束。為了方便計算 設 $f(\alpha)=\alpha$ (這裏為了簡化模型, 同時因為現實中存 在的獨立董事努力程度遠遠不足, 所以忽略努力程度 達到一定水準之後的邊際效用遞減), 所以這一最優問 題可求解得:

$$
\begin{aligned}
& \beta^{*}=\frac{\left(1-\sigma^{2} \rho b k\right)}{\left(\sigma^{2} \rho b+1\right)} \\
& \alpha^{*}=\frac{(1+k)}{b\left(\sigma^{2} \rho b+1\right)}
\end{aligned}
$$

分別對 $\beta^{*}$ 和 $\alpha^{*}$ 求 $k$ 的導數可以得到:

$$
\begin{aligned}
& \frac{\partial \beta^{*}}{\partial k}=-\frac{\sigma^{2} \rho b}{\left(\sigma^{2} \rho b+1\right)}<0 \\
& \frac{\partial \alpha^{*}}{\partial k}=\frac{1}{b\left(\sigma^{2} \rho b+1\right)}>0
\end{aligned}
$$

(5)式說明薪酬激勵與聲譽激勵是一種替代關 係, 適當聲譽激勵可以減輕企業薪酬的激勵力度, 這 在一定程度上增加了獨立懂事的獨立性, 有利於獨立 董事履行其監督職能; (6)式說明增加聲譽激勵可以使 獨立董事提高其努力水準, 更接近帕雷托最優值。

\section{3 聲譽激勵的應用設計}

本節借鑒了 Spence1974 年在其著作“Market Signalling”中提出的文憑的信號模型, 設計應用聲譽激勵 機制以區分獨立董事能力的一種構想。信號模型認為 一個具有高生產率的人會選擇具有相對優勢的行為作 為信號, 向雇主顯示自己的能力, 使雇主對其支付高 工資。信號本身具有分離勞動力的作用, 可以改變勞 動市場的配置。將該模型的核心思想運用到獨立董事 制度的分析中, 可以發現在獨立董事的勞動力市場, 聲譽激勵正是這樣一種信號, 這使區分獨立董事的能 力成為可能。

\section{1 前提}

1) 假定獨立董事分為兩種類型: 具備監管能力的 類型 (兼管型) 與不具備監管能力的類型 (非兼管型)。 設兩種類型的獨立董事從所在公司得到的薪酬相同, 都為 I。但是由於監管型獨立董事能履行其職能, 對 企業的內部人行為起到很好的約束, 故社會聲譽很 好, 所以, 從事獨立董事工作對其產生的收益設為 $\mathrm{I}+\mathrm{R}$ 。

2) 假定兩種類型的獨立董事在參加例行會議時 付出的成本相同, 用 $\mathrm{C}_{0}$ 表示; 但是未獲得一定的社會 聲譽, 提供監管意見的時候, 兩種類型的獨立董事付 出的成本有所不同, 監管型獨立董事由於個人能力較 強, 相對付出成本較少。如果用 $\mathrm{e}$ 代表非監管型獨立 董事進行監管時投入精力的努力程度, 則監管型董事 付出成本為 $\mathrm{ke},(\mathrm{k}<1)$ 。所以, 監督型獨立董事提供 監督意見的總成本為 $\mathrm{C}_{1}=\mathrm{C}_{0}+\mathrm{ke}$; 而非監管型獨立董 事, 如果提供監督意見, 需花費總成本為 $\mathrm{C}_{2}=\mathrm{C}_{0}+\mathrm{e}$ 。

顯然同樣的努力程度下, $\mathrm{C}_{1}<\mathrm{C}_{2}$ 。這是因為監督 管理不僅需要相關專業知識, 還需要克服很多來自公 司內外的阻力, 如資訊獲取成本、人際關係成本、責 任風險等。這就意味著各種不同背景的獨立董事, 由 於各方面條件的差異, 進行有力的監督管理所付出的 成本不同。我們用“監督成本”來表示, 監督成本這裏 指某人為了勝任監督型獨立董事所付出的努力成本。 如果不具備監管能力的非監管型董事勉強提供監管意 見, 需要付出很大成本 e (可以想像讓一個不具會計 背景的人士對分析企業的財務報表); 但是, 對於監督 型獨立董事來說, 為獲得上述同樣的成果, 只需成本 $k e, \quad(k<1)$ 。也就是同樣的監督行為, 監督型董事的成 本比顧問型董事的成本低。對於這一點可以做兩點解 釋:（1）監管型董事可能已具有一定的社會地位或權 威能力, 進行監管所需的額外努力成本不大; (2) 監 
管型董事不需要花很費多時間進行監管, 可以同時兼 顧其他非獨立董事的職務, 即監管的機會成本低。

\section{2 應用}

如果企業可以識別獨立董事的類型, 可根據其貢 獻支付薪酬。問題在於，企業在雇用獨立董事時，並 不能觀察到他們的類型, 因此社會對獨立董事的聲譽 反映就成為企業可以借助的信號。

企業只要找出一個努力的門檻水準 $\mathrm{e}^{*}$, 使得企業 自己可以憑藉這樣一個標準去識別不同類型的獨立董 事。企業希望 $\mathrm{e}^{*}$ 具有下列功能：對於一個獨立董事, 如果他願意提供的努力水準 $\mathrm{e} \geq \mathrm{e}^{*}$, 就說明其收益為 $\mathrm{I}+\mathrm{R} ，$ 因此就可以認為他適合監管，屬於監管型獨立 董事; 而如果獨立董事提供的努力水準 $\mathrm{e}<\mathrm{e}^{*}$, 則可 判斷該董事屬於非監管型董事, 不適合監管, 只能得 到收益 I。

這裏為了簡化模型設獨立董事的收益只有兩檔工 資, 如果 $\mathrm{e} \geq \mathrm{e}^{*}$, 則 $\mathrm{I}_{1}=I+R$; 如果 $\mathrm{e}<\mathrm{e}^{*}$, 則 $\mathrm{I}_{2}=\mathrm{I}$ 。從 這種收益政策出發, 獨立董事對其努力程度的選擇也 只有兩種: 如果決定提供 $\mathrm{e}<\mathrm{e}^{*}$, 則只選擇 $\mathrm{e}=0$, 而非 $\mathrm{e}<\mathrm{e}^{*}$ 的其他情沉, 因為反正工資只有 $\mathrm{I}$, 無須對監督 作出努力; 而如果決定提供 $\mathrm{e} \geq \mathrm{e}^{*}$, 會得到工資 $\mathrm{I}+\mathrm{R}$, 則理性選擇是 $\mathrm{e}=\mathrm{e}^{*}$, 因為如果選擇 $\mathrm{e}>\mathrm{e}^{*}$, 只會白費 工夫, 因為工資為確定。

在以上前提條件下, 總結收入、成本函數如下:

1) 監管型董事: 如果選擇 $\mathrm{e}=\mathrm{e}^{*}$, 收益函數為 $\mathrm{I}_{1}$ $=\mathrm{I}+\mathrm{R}$, 成本函數為 $\mathrm{C}_{1}{ }^{*}=\mathrm{C}_{0}+\mathrm{k} \mathrm{e}^{*}$; 如果選擇 $\mathrm{e}=0$, 收入函數為 $\mathrm{I}_{2}=\mathrm{I}$, 成本函數為 $\mathrm{C}_{1}=\mathrm{C}_{0}$ 。

2) 非監管型董事: 如果選擇 $\mathrm{e}=\mathrm{e}^{*}$, 收益函數為 $\mathrm{I}_{1}=\mathrm{I}+\mathrm{R}$, 成本函數為 $\mathrm{C}_{2}=\mathrm{C}_{0}+\mathrm{e}^{*}$; 如果選擇 $\mathrm{e}=0$, 收入函數為 $\mathrm{I}_{2}=\mathrm{I}$, 成本函數為 $\mathrm{C}_{2}{ }^{*}=\mathrm{C}_{0}$ 。

為讓企業的信念得到證實, 我們期望監管型獨立 董事能夠主動偏好於 $\mathrm{e}=\mathrm{e}^{*}$, 而非 $\mathrm{e}=0$, 而非監管型 獨立董事會偏好 $\mathrm{e}=0$, 而不是 $\mathrm{e}=\mathrm{e}^{*}$ 。根據理性人假 定, 如果讓這種預期合理, 需要滿足兩個條件: 監督 型獨立董事選擇 $\mathrm{e}=\mathrm{e}^{*}$ 的收益大於其選擇 $\mathrm{e}=0$ 的得 益; 而非監管型獨立董事選擇 $\mathrm{e}=0$ 的收益大於其選擇 $\mathrm{e}=\mathrm{e}^{*}$ 的得益。這組激勵——相容約束條件可以寫成

$$
\begin{gathered}
\left\{\begin{array}{rr}
W_{1}-C_{1}^{*}>W_{2}-C_{1} & \text { 監督型董事 } \\
W_{2}-C_{2}^{*}>W_{1}-C_{2} & \text { 顧問型董事 }
\end{array}\right. \\
\Rightarrow\left\{\begin{array}{r}
h w-C_{0}-k e^{*}>w-C_{0} \\
w-C_{0}>h w-C_{0}-e^{*}
\end{array}\right.
\end{gathered}
$$

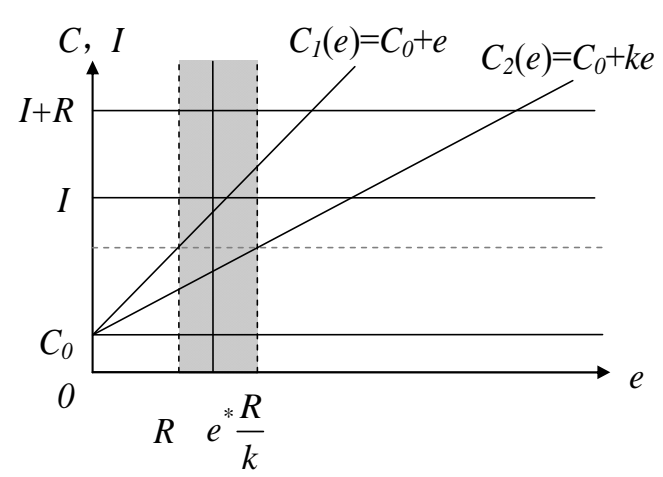

圖 3. 聲譽激勵的信號功能

Figure 3. the signal function of RIM

解這個不等式組得:

$$
(h-1) w<e^{*}<\frac{h-1}{k} w
$$

當這一條件滿足時, 企業的願望與信念會得到實 現: 所有選擇 $\mathrm{e} \geq \mathrm{e}^{*}$ 的董事的確是監管型董事; 所有 選擇 $\mathrm{e}<\mathrm{e}^{*}$ 的董事確實是非監管型董事。圖 3 給出了 努力 $\mathrm{e}$, 工資 $\mathrm{I}$, 與工作總成本 $\mathrm{C}$ 之間的關係。

從圖裏可以看出, 當 $\mathrm{e}^{*}=\mathrm{R}$ 時, 非監管型董事選 擇 $e=0$ 或 $e=e^{*}$ 的收益是一樣的, 即 $I-C_{0}=I+R-C_{0}-e_{\text {。 }}$ 而 當 $\mathrm{e}^{*}=\mathrm{R} / \mathrm{k}$ 時, 監管型獨立董事選擇兩種行為的收益是 一樣的, 即 $\mathrm{I}-\mathrm{C}_{0}=\mathrm{I}+\mathrm{R}-\mathrm{C}_{0}-\mathrm{ke}$ 。所以當 $\mathrm{R}<\mathrm{e}^{*}<\mathrm{R} / \mathrm{k}$ 時, 監 管型獨立董事選擇 $\mathrm{e}=\mathrm{e}^{*}$ 的收益較多, 而同時非監管型 獨立董事選擇 $\mathrm{e}=0$ 的收益較多。這樣一來, 聲譽激勵 機制就如實地反映了獨立董事的能力, 獲得聲譽收益 的獨立董事履行其職能, 剩餘不好的獨立董事被企業 發現並不適合履行監管職能, 因此, 聲譽激勵機制的 應用可以改善資訊不對稱情況。

\section{4 結論}

本文從委託一代理理論的角度, 通過對獨立董事 激勵機制的研究, 得出如下結論:

1）由於存在資訊不對稱，獨立董事和委託人基於 各自利益最大化而做出的決策使制度的運作不能達到 帕累托最優的結果。固定薪酬制度能夠保持獨立董事 的獨立性, 但是激勵不足; 與企業業績相關的激勵機 制可以在一定程度上提高獨立董事的積極性，但是對 其獨立性有很大影響。

2) 聲譽激勵機制與企業的業績相關的激勵機制 具有一定的替代性, 並且給予恰當的激勵可以使獨立 董事的最終決策以及企業的行為更加接近社會總體的 
帕累托最優結果。

3) 聲譽激勵機制可以改善獨立董事與委託人之 間的資訊不對稱情況，通過制度設計可以識別具有監管 能力的獨立董事, 為獨立董事制度的有效運作提供參考。

本文通過模型, 從理論上證明了聲譽激勵機制在 解決獨立董事“獨立性悖論”中的重要作用。同時提出 通過適當的制度安排，聲譽激勵機制可以改善資訊不 對稱情況, 在識別獨立董事能力方面能起到積極作 用。但是, 文中提到的“努力程度”這一概念, 比較抽 象, 實踐中需要上市公司根據各自具體情況進行量 化, 具體的衡量方法有待於進一步擴展研究。

\section{REFERENCES}

[1] Qiu, F. and Zhang, Q., "A Game analysis of independent director's incentive restraint mechanisms in China [J]," Contemporary Finance and Economics, No. 5, pp. 67-70, 2006. (In Chinese)
[2] Li, H. M. and Song, M. Y., "A study on the independent director's incentive compensation $[\mathrm{J}]$," The Economic Forum, No. 6, pp. 79-82, 2007.(In Chinese)

[3] Luo, D. L., Xu, X., and Feng, Y., "The formation of independent director's compensation mechanism-A case study of China's listed companies [J]," Management Science, No. 2, pp. 46-53, 2007. (In Chinese)

[4] Jian, X. H. and Shi H. W., "The 'independence paradox' of independent directors and the design of the effective exercise system [J]," Chinese industrial economy, No. 3, pp. 60-67, 2006. (In Chinese)

[5] Holmstrom and Bengt, "Moral Hazard in Teams [J]," Bell Journal of Economics, Vol. 13, pp. 324-340, 1982.

[6] Fama and Jensen, "Separation of ownership and control [J]," Journal of law and economics, No. 2, pp. 301-305, 1983. 